\title{
Microstructure and Flight Behaviors of Droplet and its Solidification in Twin-Wire Arc Sprayed Ni-Al Composite Coatings
}

\author{
Jixiao Wang ${ }^{a *}$, Yongdong Wang ${ }^{a}$, Jingshun Liu ${ }^{c}$, Lunyong Zhang ${ }^{d}$, Limin Gao ${ }^{a}$, Guanghai Zheng ${ }^{a}$, \\ Hongxian Shen ${ }^{b}$, Jianfei Sun \\ ${ }^{a}$ School of Materials Science and Engineering, Heilongjiang University of Science and Technology, \\ 150022, Harbin, China \\ ${ }^{b}$ School of Materials Science and Engineering, Harbin Institute of Technology, 150001, Harbin, China \\ ${ }^{c}$ School of Materials Science and Engineering, Inner Mongolia University of Technology, 010051, \\ Hohhot, China \\ ${ }^{d}$ Max Plank POSTECH Center for Complex Phase Materials, Max Planck POSTECH/Korea Research \\ Initiative, Pohang 790-784, Republic of Korea
}

Received: April 22, 2017; Revised: January 09, 2018; Accepted: February 20, 2018

\begin{abstract}
Droplet flight and solidification behaviors during twin-wire arc sprayed (TWAS) composite coatings were systematically investigated. Both theoretical model and numerical method were established for calculating the droplet deformation, breakup and solidification process in air flow based on the volume of fluid (VOF) dual-phase flow model jointed with the standard k- $\varepsilon$ model. The experimental simulation results indicate that TWAS droplet is broken through explosion or two steps breaking process. The calculation of TWAS gas flight dynamics demonstrates that the TWAS particles are accelerated at first and then slowed down. Microstructure of the TWAS prepared Ni-5wt.\%Al and Ni-20wt.\%Al composite coating was accordingly characterized by XRD, SEM and TEM, so the phase compositions of the $\mathrm{Ni}-\mathrm{Al}$ composite coatings were obtained. TEM analysis also showed that an amorphous phase was formed according to the characteristic of diffraction ring in Ni matrix solid solution at an original state.
\end{abstract}

Keywords: Twin-wire arc sprayed, composite coatings, breakup behavior, flight dynamics, microstructures.

\section{Introduction}

The wire tip is melted and sprayed on a fine droplet through dry compressed air in the twin-wire arc spraying technique (TWAS) for preparing composite coatings. The state of the droplet largely influences the coating structure and properties. Generally, droplet particles with higher velocity would generate coating of higher quality in TWAS. The droplet deformation and breakup are very complicate at high velocity region ${ }^{1,2}$. The research for the droplet breakup through coating microstructure analysis and evaluation is necessary for optimizing the TWAS thus enhancing the coating performance ${ }^{3-5}$.

Droplets flight in low velocity region, such as natural air flow, has been investigated by $\mathrm{Hu}^{6}$ and Blackwell $\mathrm{BC}^{7}$. According to the difference of Weber number, the droplet goes through the varied stages successively with shock breakup, bag breakup, multi-pattern breakup, shear breakup and explosive breakup. Milind $\mathrm{K}^{8}$ revealed the first and the second dispersed droplets were formed in the atomization gas. The size distribution of the dispersed droplets obeys a simple normal distribution. The pressure of atomized gas mainly determines the final Reynolds number of the flying droplet. The deformation and solidification behaviors of the molten droplet influence the porosity, bonding strength and surface roughness of coatings ${ }^{9-11}$. With the increase of both velocity and temperature for the molten particles, surface roughness and porosity of the coating decrease. The flat deformation process occurs during the process of TWAS. Higher impact velocity induces higher coating density and stronger bonding force of the flat particles. Therefore, it is more significant to investigate their deformation and solidification of droplets with a high impact velocity ${ }^{12-14}$. In this paper, the volume of fluid method is adopted to track the free surface and the interface of the collision between the droplet and the substrate. Theoretical models were established and the processes of deformation and solidification were analyzed. Through characterization of microstructures of a TWAS Ni-Al coatings, the droplet breakup and solidification behaviors were experimentally studied.

\section{TWAS flight dynamics}

In order to analyze and simplify the evolution of droplets during the flight, the interaction among droplets is neglected. The conveyed characteristics are introduced to describe spray droplet particles in the air by single droplet particle. Assuming 
the high-velocity air flow is isokinetic and isothermal, and droplet particle is spherical. The key point of this analysis is the instability of the droplet particles and the change of the droplet velocity with the time or the flight distance. The heat transfer of the spray droplets in high temperature and high velocity air flow mainly includes the convection transfer and the radiation between the droplet particles and the air flow. The convection mode would be dominant in consideration of that the droplet particles are heated in the air flow. Physical parameters for numerical analysis are listed in Table $1^{15-18}$.

According to the Lagrangian motion, equation of particles can be obtained as follows:

$$
u_{p}=u_{g 0}\left(1-\frac{1}{u_{g 0} C_{1} t+1}\right)
$$

Formula (1) is applied for calculating the flight time of the spray droplet particles. where $\mathrm{p}$ - particle, $\mathrm{g}$ - gas, $u_{\mathrm{p}}$ - particle velocity, $\mathrm{u}_{\mathrm{g} 0}$ - gas velocity, $\rho_{\mathrm{g}}$ - mass density of gas, $\rho_{\mathrm{p}}$ - density of particles, $\mathrm{d}_{\mathrm{p}}$ - particle diameter, $C_{1}$ $0.33 \rho_{\mathrm{g}} / \mathrm{d}_{\mathrm{p}} \cdot \rho_{\mathrm{p}}, \mathrm{t}$ - particle flight time.

In addition, the relationship between the flight distance and the flight velocity of the droplets can be obtained by the integral operation:

$$
L_{p}=\frac{1}{C_{1}}\left(\frac{u_{g 0}}{u_{g 0}-u_{p}}-\ln \frac{u_{g 0}}{u_{g 0}-u_{p}}-1\right)
$$

where $\mathrm{L}_{\mathrm{p}}$ - flight distance of droplet particles.

Relationship between the temperature and the flight time of droplet particles as follows:

$$
T_{p}=T_{0}+T_{g 0} e^{\frac{-6 \alpha}{d_{P} \rho_{P} C_{P}} t}
$$

where $T_{p}$ - particle temperature, $T_{0}$ - room temperature $(300 \mathrm{~K}), \mathrm{T}_{\mathrm{g} 0}$ - air temperature, $\alpha$ - heat transfer coefficient, $C_{p}$ - specific heat of particles, $d_{p}$ - particle diameter, $\rho_{p}$ density of particles, $\mathrm{t}$ - particle flight time.

Fig. 1 illustrates the relationships among the velocity, time and flight distance of $\mathrm{Ni}-\mathrm{Al}$ droplet. The acceleration of droplet is relatively slow. Assuming the spraying distance is around $200 \mathrm{~mm}$, the larger molten droplets with $50 \mu \mathrm{m}$ diameter reaching the surface of the work piece can get a velocity up to $15 \%$ of the gas velocity. The larger the diameter of droplet is, the smaller the flying velocity is. This also indicates that the size of the droplet is an important factor impacting the final droplet velocity. Fig. 1c indicates that the gas velocity is the most vital factor to determine the velocity of droplet. The velocity of the particle with $25 \mu \mathrm{m}$ diameter can get only $\sim 80 \mathrm{~m} / \mathrm{s}$ when the gas velocity is $200 \mathrm{~m} / \mathrm{s}$, and its velocity reaches $\sim 260 \mathrm{~m} / \mathrm{s}$ when the gas velocity is 1000 $\mathrm{m} / \mathrm{s}$. That is to say, the velocity of the particles increases as the gas velocity increases. In addition, the gas pressure also has a greater impaction on the velocity of particles (as shown in Fig. 1d).

Fig. 2 is the relationships between the particle temperature and the flight time. The droplet particles temperature first is increased to a stable magnitude (Fig. 2a) and then slowly decreased during the flight. The cooling rate of the large droplets is lower than that of small droplets during the TWAS process. With the increase of the flight time, the temperature of droplet particles in atomization gas is quickly reduced until reaching room temperature. The wider the droplet particle velocity spans, the higher the droplet particle velocity in the air is and the shorter oxidation exposure time is, thus the coating possesses a relatively higher bonding strength and density.

\section{Atomization droplet breakup behavior}

Arc spraying process is a complicated process and the dynamics of droplet formation is modulated by both the atomization gas and the arc. The detailed simulation process is displayed about atomization droplets. Thermo-physical properties of flame gas and particle are listed in Table $2^{15-18}$.

Fig. 3 shows the deformation and breakup process at different time for a droplet with initial $\varnothing 1.6 \mathrm{~mm}$ and at atomization gas pressure $0.3 \mathrm{MPa}$. All the color bar units are temperature $\mathrm{K}$ in the paper. The droplet particles become crescent at $\sim 10 \mu \mathrm{s}$, and the center of the droplet begins to break at $\sim 20 \mu \mathrm{s}$. Between $20 \mu \mathrm{s}$ and $30 \mu \mathrm{s}$, droplet particles undergo a transition from the first breakup to the second breakup process. The second breakup is completed at $50 \mu \mathrm{s}$, and the particles of the region become fewer at $80 \mu$ s. Subsequently, the breakup particles quickly fly out of the computational region. During this process, the droplet particles are firstly deformed, and then the droplet particles proceeded the first breakup, followed by the second breakup.

In the above process, the droplet particle breakup is explosive type. The calculation region of flight distance is $\sim 45 \mathrm{~mm}$, and the time is $80 \mu \mathrm{s}$. The droplet particle velocity reaches $\sim 562.5 \mathrm{~m} / \mathrm{s}$ when the atomization pressure

Table 1. Related processing parameters for numerical analysis.

\begin{tabular}{lcccccc}
\hline Materials & $\begin{array}{c}\text { Melting point } \\
(\mathrm{K})\end{array}$ & $\begin{array}{c}\text { Density } \\
\left(\mathrm{kg} \cdot \mathrm{m}^{-3}\right)\end{array}$ & $\begin{array}{c}\text { Specific heat } \\
\left(\mathrm{J} \cdot \mathrm{kg}^{-1} \cdot \mathrm{K}^{-1}\right)\end{array}$ & $\begin{array}{c}\text { Thermal } \\
\text { conductivity } \\
\left(\mathrm{W} \cdot \mathrm{m}^{-1} \cdot \mathrm{K}^{-1}\right)\end{array}$ & $\begin{array}{c}\text { Kinematic } \\
\text { viscosity } \times 10^{6} \\
(\mathrm{~Pa} \cdot \mathrm{s})\end{array}$ & $\begin{array}{c}\text { Molar mass } \\
\left(\mathrm{g} \cdot \mathrm{mol}^{-1}\right)\end{array}$ \\
\hline Ni-Al & 1728 & 8591 & 481 & 97.273 & 5000 & 57.1 \\
Air & - & 1.225 & 1006 & 0.024 & 113.3 & 29 \\
$6061-\mathrm{T} 6$ & 925 & 2710 & 871 & 202.4 & - & - \\
\hline
\end{tabular}




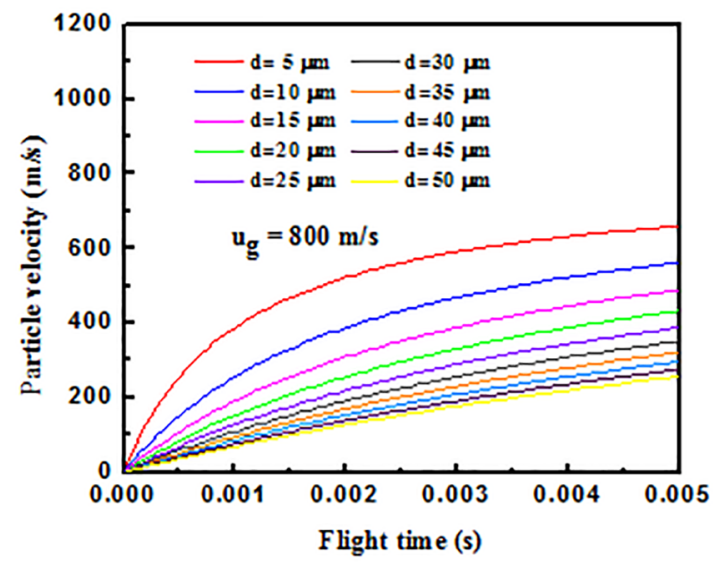

(a) Flight time

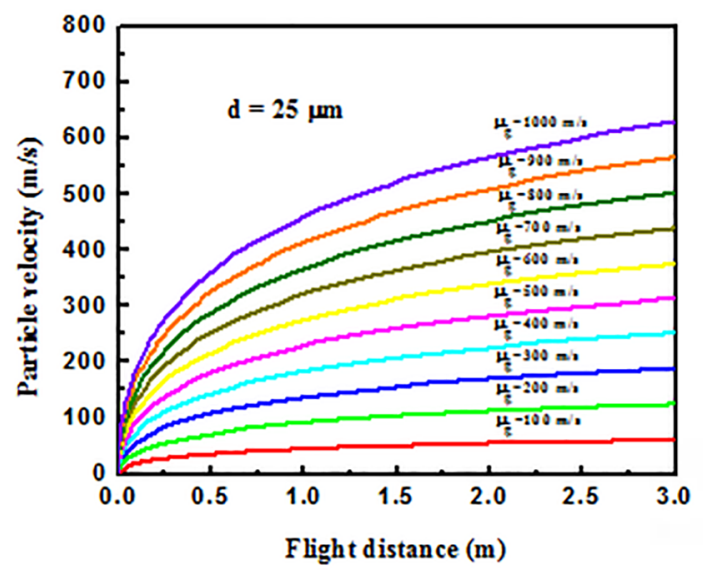

(c) Gas velocity

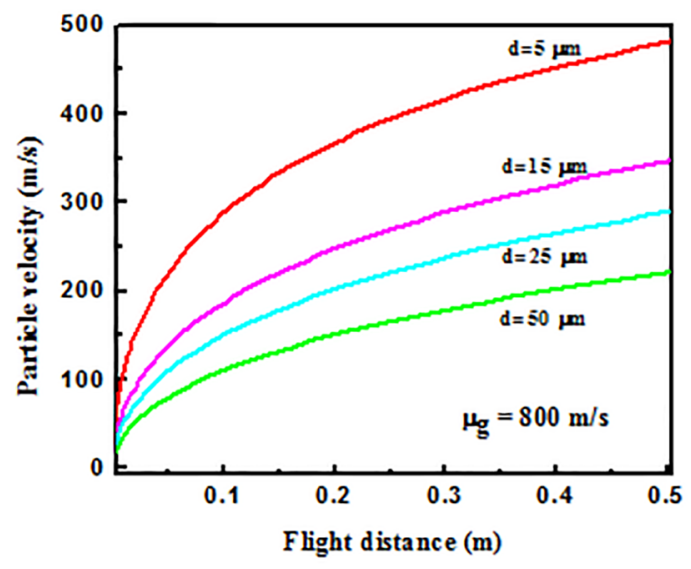

(b) Flight distance

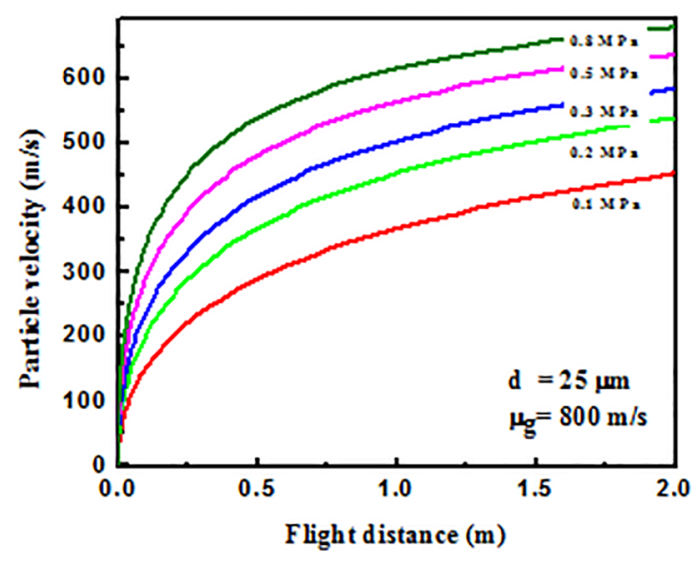

(d) Gas pressure

Figure 1. Relationships between the particle velocity and spraying parameters for flight time (a), flight distance (b), gas velocity (c), and gas pressure (d)

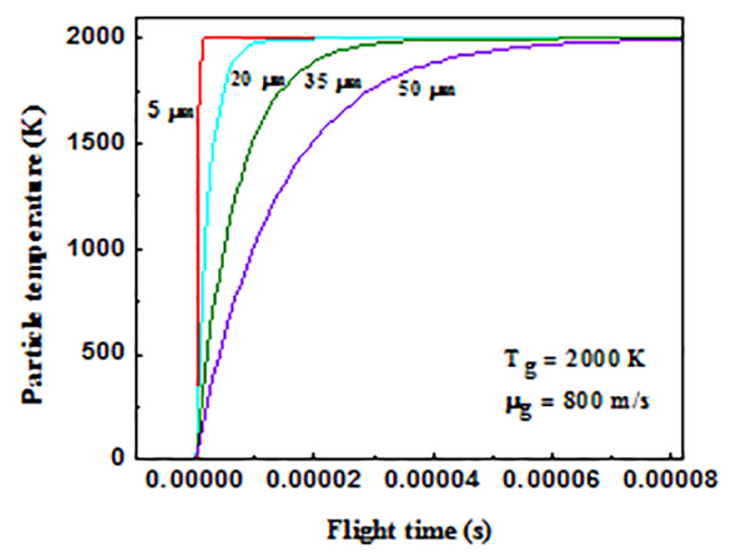

(a) Flight time

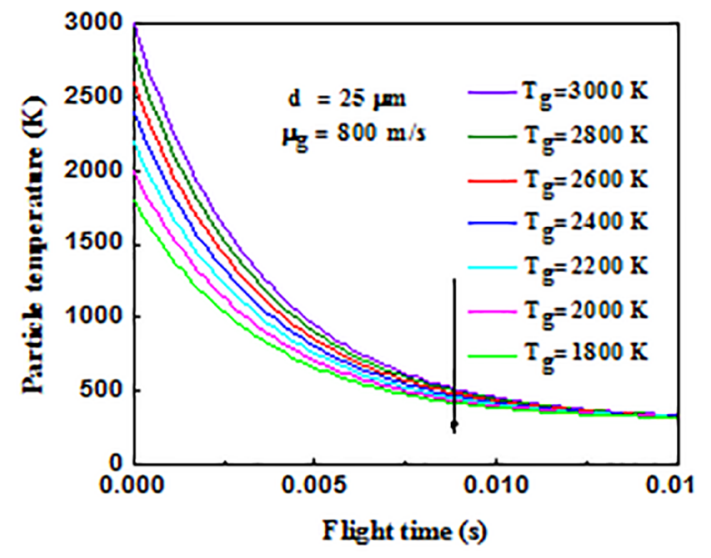

(b) Flight time

Figure 2. Relationships between the particle temperature and flight time (a) and (b) 
Table 2. Thermo-physical property indexes of flame gas and particles.

\begin{tabular}{lcccccc}
\hline Material & Temperature $(\mathrm{K})$ & Density $\left(\mathrm{kg} \cdot \mathrm{m}^{-3}\right)$ & $\begin{array}{c}\text { Specific heat } \\
\left(\mathrm{J} \cdot \mathrm{kg}^{-1} \cdot \mathrm{K}^{-1}\right)\end{array}$ & $\begin{array}{c}\text { Thermal } \\
\text { conductivity } \\
\left(\mathrm{W} \cdot \mathrm{m}^{-1} \cdot \mathrm{K}^{-1}\right)\end{array}$ & $\begin{array}{c}\text { Kinematic } \\
\text { viscosity } \times 10^{6} \\
(\mathrm{~Pa} \cdot \mathrm{s})\end{array}$ & $\begin{array}{c}\text { Dynamic } \\
\text { viscosity } \times 10^{6} \\
\left(\mathrm{~m}^{2} \cdot \mathrm{s}^{-1}\right)\end{array}$ \\
\hline Flame gas & 1273 & 0.275 & 1306 & 0.109 & 48.4 & 176 \\
Atomized flow & 2400 & 1.225 & 1006 & 0.024 & 113.3 & 92.5 \\
Ni-Al & - & 8591 & 481 & 97.273 & 5000 & 0.58 \\
\hline
\end{tabular}

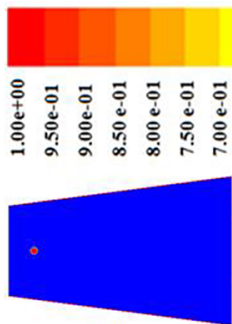

$0 \mu \mathrm{s}$

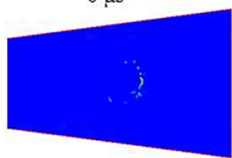

$30 \mu \mathrm{s}$

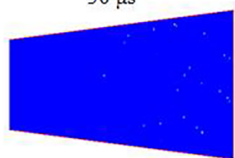

$60 \mu \mathrm{s}$

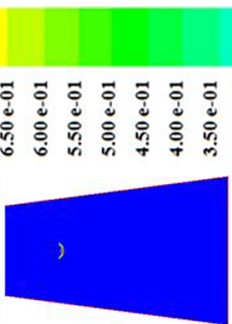

$10 \mu \mathrm{s}$

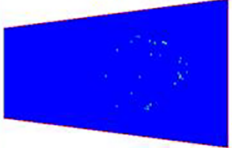

$40 \mu \mathrm{s}$

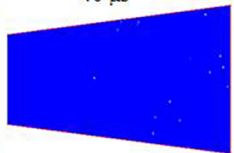

$70 \mu \mathrm{s}$
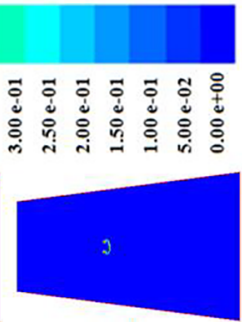

$20 \mu \mathrm{s}$

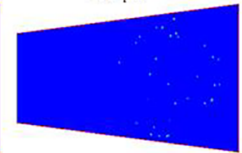

$50 \mu \mathrm{s}$

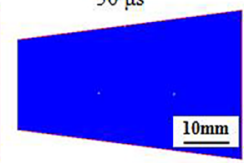

$80 \mu \mathrm{s}$
Figure 3. Time dependence of TWAS atomized droplet breakup process

is $0.5 \mathrm{MPa}$, much faster than the sonic velocity, satisfies the basic requirements of coating during the spraying process. A larger pressure can result in a faster cooling of the broken particles, but the bonding strength will be decreased after final solidification.

Fig. 4 shows the deformation and the breakup process at $10 \mu$ s with the droplet diameter of $1.6 \mathrm{~mm}$ and the pressure range of $0.2 \mathrm{MPa} \sim 0.7 \mathrm{MPa}$. At $0.5 \mathrm{MPa}$, the crescent center suffers the first breakup, and can cause the second breakup between $0.5 \mathrm{MPa}$ and $0.6 \mathrm{MPa}$. With the pressure increase, the droplet particles firstly are deformed and then the first broken, followed by the second breakup, and finally formed a stable phase.

Fig. 5 indicates the deformation and breakup process at $30 \mu$ s with the droplet diameter of $0.8 \sim 3.2 \mathrm{~mm}$ and pressure of $\sim 0.5 \mathrm{MPa}$. The particles are completely broken at $30 \mu \mathrm{s}$ when the diameter of droplet is between $0.8 \mathrm{~mm}$ and $1.6 \mathrm{~mm}$. Droplet particles with a diameter of $2.4 \mathrm{~mm}$ are broken at 30 $\mu$ s at the beginning of the second breakup, but the particles with diameter of $3.2 \mathrm{~mm}$ are still at the deformation stage at $30 \mu \mathrm{s}$, no breakup. Higher pressure is requested to break the molten droplet particles. Fig. 6 shows the dependence of gas velocity on the atomized pressure. With the increase of atomizing gas pressure, the gas velocity obviously increases. The practical spraying particle velocity can about reach

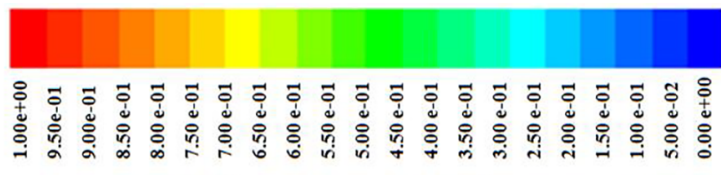

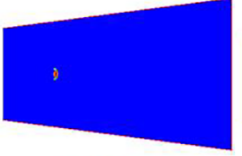

$0.2 \mathrm{MPa}$

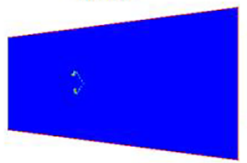

$0.5 \mathrm{MPa}$

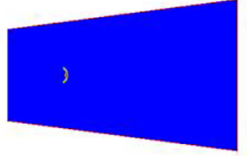

$0.3 \mathrm{MPa}$

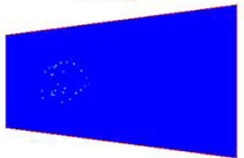

$0.6 \mathrm{MPa}$

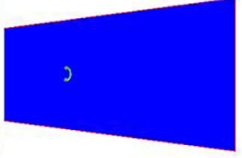

$0.4 \mathrm{MPa}$

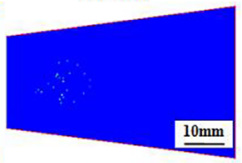

$0.7 \mathrm{MPa}$
Figure 4. Pressure dependence of TWAS atomized droplet breakup process

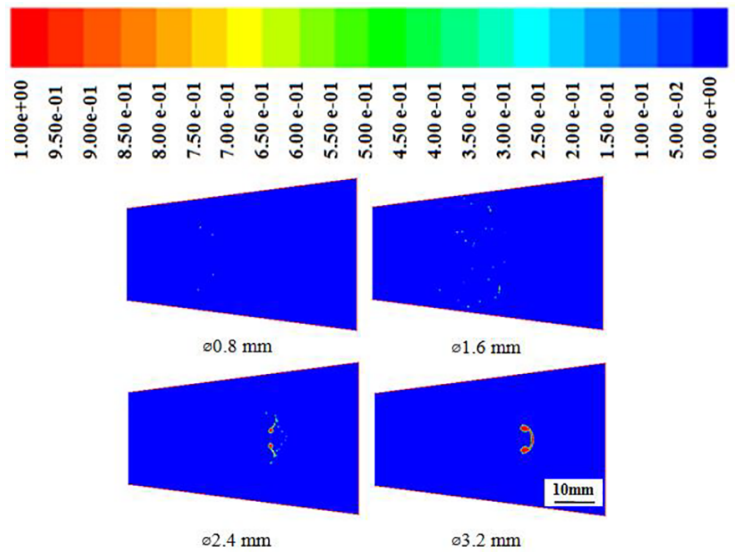

Figure 5. Diameters dependence of TWAS atomized droplet breakup for $0.5 \mathrm{MPa}$ at $30 \mu \mathrm{s}$

$\sim 20 \%$ of the gas velocity, so the spraying particle velocity is still relatively lower as for the material and the spraying distance are different.

Through the following formula of Weber number: $W e=\rho_{g} d_{0} U_{0}{ }^{2} / \sigma$, where $\rho_{\mathrm{g}}$ is the atomization gas density, $\mathrm{d}_{0}$ is the droplet diameter, $U_{0}$ is the atomization gas velocity, $\sigma$ is the surface tension. The relationships between the atomization gas pressure and Weber number for four-kind diameters are obtained through both the gas pressure and the velocity as shown in Fig. 6. With the increase of pressure and the droplet diameter, the Weber number increases. Between 0.2 $\mathrm{MPa}$ and $0.8 \mathrm{MPa}$, the Weber number of the $1.6 \mathrm{~mm}$ diameter droplet is in the range of 359.2 1436.7. 


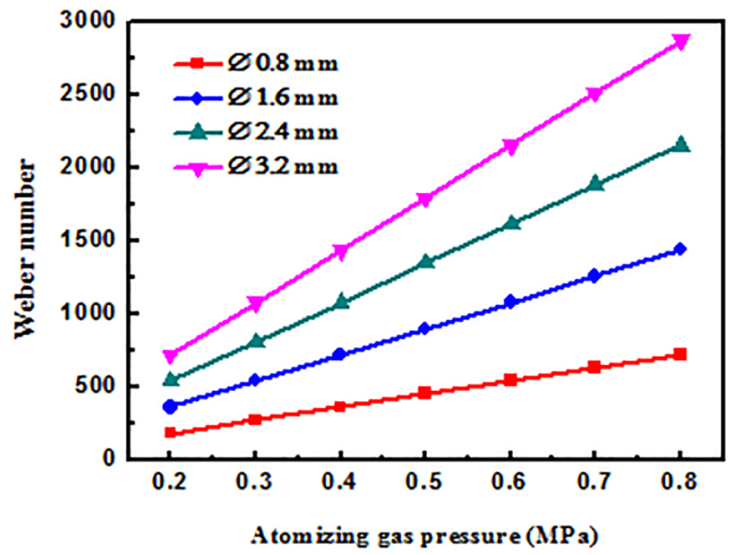

Figure 6. Relationships between atomizing gas pressure and Weber number

\section{Atomization droplet impact and solidification behavior}

Fig. 7 shows the deformation and solidification process of a droplet. With the time extension, the droplet spreads quickly and the spreading diameter decreases to $234.4 \mu \mathrm{m}$ at $0.2 \mu$ s with spreading thickness of $6.28 \mu \mathrm{m}$; the spreading diameter reaches $637.6 \mu \mathrm{m}$ at $1 \mu \mathrm{s}$.

Fig. 8 shows the deformation of the droplet on the substrate. With the velocity increasing, the degree of particles flatten becomes aggravated. With the increase of the droplet size, both spreading diameter and thickness of the corresponding width are increased. Generally, larger size droplet under high velocity impact will form larger diameter flattened particles.
Fig. 9 shows the relationship between the diameter and the thickness of droplet spreading and solidification time. With the extension of the deformation time, the droplet spreading diameter shows an increasing trend. Meanwhile, the larger droplet diameter and the higher velocity are corresponding to the larger spreading diameter. The spreading diameter tends to be stable after $1 \mu \mathrm{s}$. As shown in Fig. 9b, the thickness of the spreading droplet is reduced with the extension of deformation time. This spreading thickness is enhanced with the increase of the droplet volume and the decrease of the velocity.

Fig. 10 shows the time dependence of droplet solidification temperature field of a droplet with diameter of $50 \mu \mathrm{m}$ and velocity of $200 \mathrm{~m} / \mathrm{s}$. With the time increasing, the area of droplet temperature field becomes larger. The flying edge phenomenon can be easily generated for small droplet particles at higher velocity. With the increase of droplet spreading time on the substrate, flat particle radius increases, and the heat diffusion region extends to the surrounding region along $\mathrm{Y}$ axis from the center. Due to the high velocity at the axis center, the temperature decreases rapidly along the $\mathrm{Y}$ axis.

Fig. 11 shows the TWAS melt droplet solidification temperature field of a $50 \mu \mathrm{m}$ diameter droplet at the moment of $1 \mu \mathrm{s}$ with the particle velocity. For the droplet particles of $50 \mu \mathrm{m}$ diameter, the temperature field becomes larger with the increase of velocity. The small size droplet particle under the high impact velocity has fast solidification. The high velocity can keep a certain temperature and form some semi-solid flattened particles.
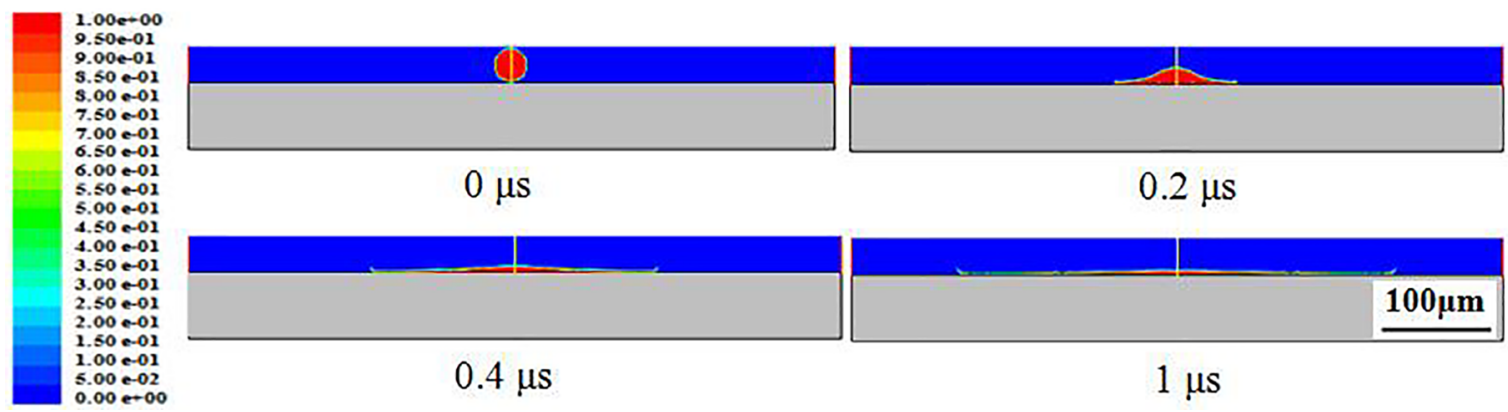

$0.2 \mu \mathrm{s}$

$0.4 \mu \mathrm{s}$

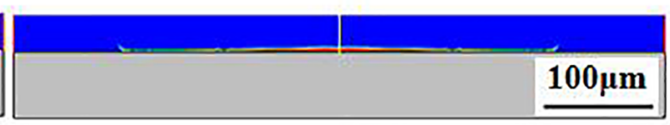

$1 \mu \mathrm{s}$

Figure 7. Changes of a droplet deformation and solidification with time for $Ø 50 \mu \mathrm{m}$ and $200 \mathrm{~m} / \mathrm{s}$

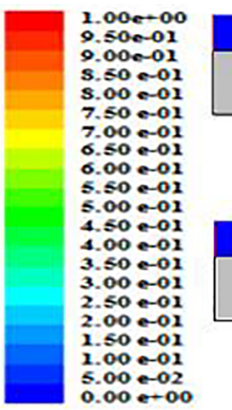

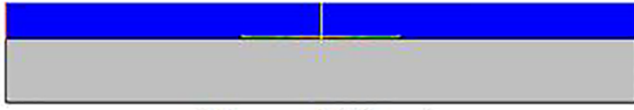

$25 \mu \mathrm{m}, 100 \mathrm{~m} / \mathrm{s}$

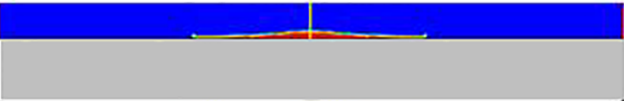

$50 \mu \mathrm{m}, 100 \mathrm{~m} / \mathrm{s}$

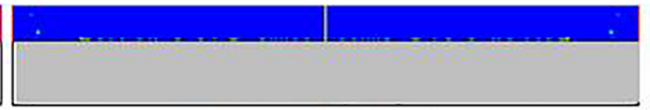

$25 \mu \mathrm{m}, 400 \mathrm{~m} / \mathrm{s}$

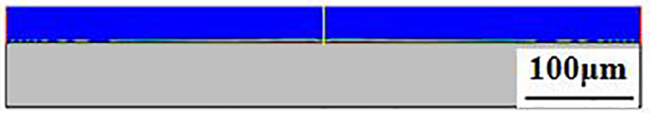

$50 \mu \mathrm{m}, 400 \mathrm{~m} / \mathrm{s}$

Figure 8. Changes of droplet deformation and solidification with diameter and velocity at $1 \mu \mathrm{s}$ 


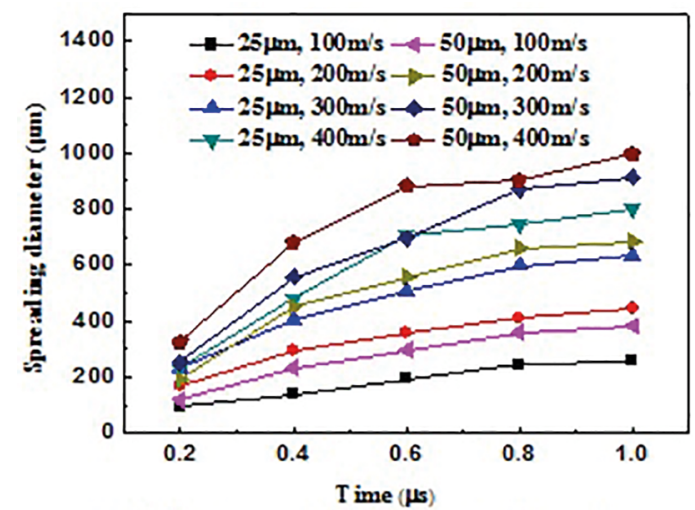

(a) Time and spreading diameter

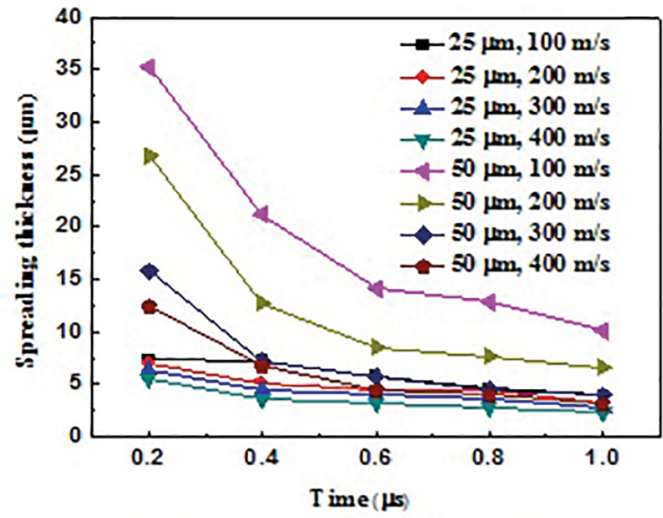

(b) Time and spreading thickness

Figure 9. Relationships between droplet spreading diameter and solidification time for (a), and between spreading thickness and solidification time for (b)

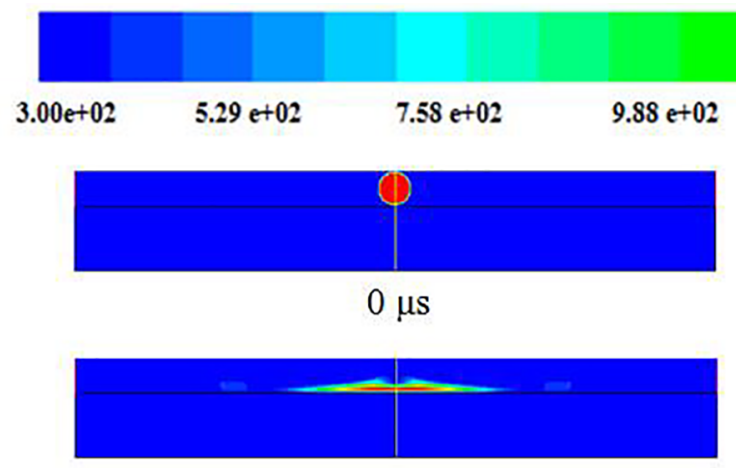

$0.6 \mu \mathrm{s}$

\section{$\begin{array}{llll}1.22 \mathrm{e}+03 & 1.45 \mathrm{e}+03 & 1.68 \mathrm{e}+03 \quad 1.83 \mathrm{e}+03\end{array}$}

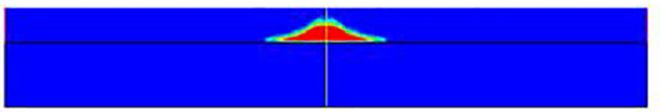

$0.2 \mu \mathrm{s}$

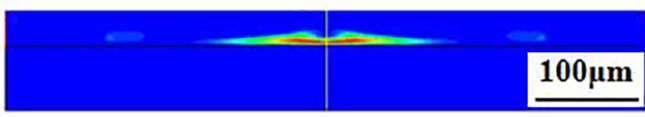

$1 \mu \mathrm{s}$

Figure 10. Changes of a droplet temperature field with time for $Ø 50 \mu \mathrm{m}$ and $200 \mathrm{~m} / \mathrm{s}$

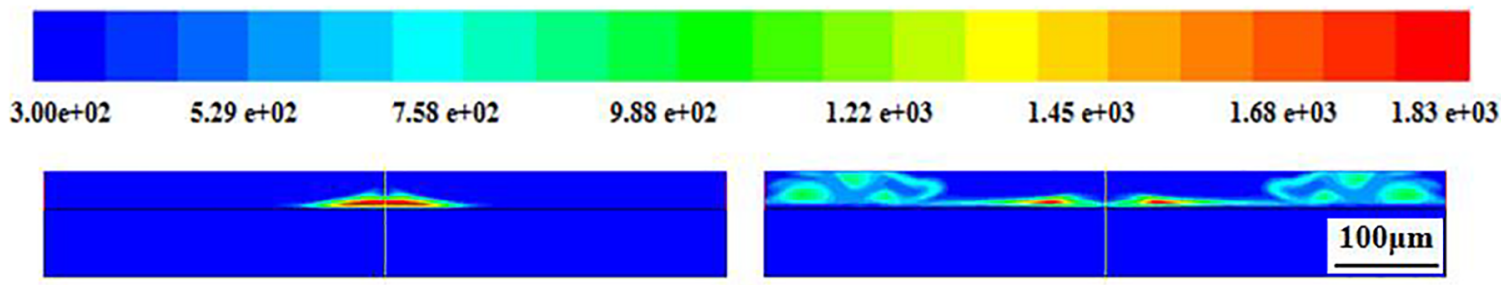

$50 \mu \mathrm{m}, 100 \mathrm{~m} / \mathrm{s}$

$50 \mu \mathrm{m}, 400 \mathrm{~m} / \mathrm{s}$

Figure 11. Changes of temperature field with velocity for a droplet diameter of $50 \mu \mathrm{m}$ and $1 \mu \mathrm{s}$

Fig. 12 reveals the relationships between temperature and time, and the maximum temperature value is extracted at different time for a $50 \mu \mathrm{m}$ diameter droplet. It can be seen that the cooling of the droplet is quite fast at the range of $0 \sim 10 \mu$ s. The temperature decreasing procedure is extended roughly to $50 \mu \mathrm{s}$. After $50 \mu \mathrm{s}$, all molten droplets tend to near room temperature, and these can be calculated from the rate of solidification of the molten droplet range of 3.1 7.6 $\left(\times 10^{7} \mathrm{~K} / \mathrm{s}\right)$. Therefore, twin-wire arc sprayed coating has a characteristic of rapid solidification.

\section{Characteristics of powder and microstructure of $\mathrm{Ni}-\mathrm{Al}$ coatings}

Generally, the Ni-Al powder under different technological parameters is mostly collected by using water. Processing parameters for the Ni-Al powders are listed in Table $3^{19,20}$. The obtained Ni-Al powder is precipitated for final collection, closed and under $373 \mathrm{~K}$ drying for $2 \mathrm{~h}$. The surface and cross-section morphology of $\mathrm{Ni}-\mathrm{Al}$ powder is observed by SEM. 


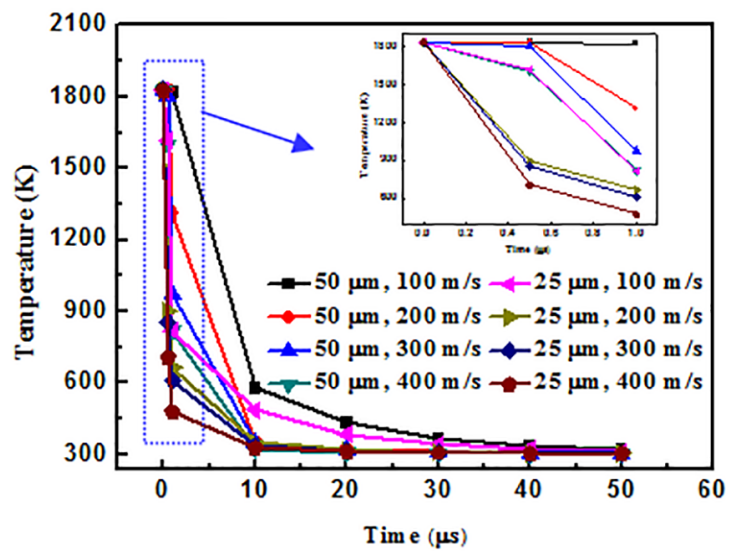

Figure 12. Relationships between droplet solidification temperature and impact time

The surface morphology of Ni-Al powder for $0.3 \mathrm{MPa}$ is shown in Fig. 13. The particle size is mostly less than 50 $\mu \mathrm{m}$ and possesses a high spherical degree. There is almost no obvious difference for two kinds of molten particles, which is composed of $\mathrm{Al}_{2} \mathrm{O}_{3}, \mathrm{Ni}-\mathrm{Al}$ compounds and $\mathrm{NiO}$. Some special particles are collected to conduct the surface line scanning and EDS. Fig. 13b shows that $\mathrm{Ni}-\mathrm{Al}$ powder cross-section morphology exhibits a variety of shapes, including the dendrite type, which mostly consists of $\mathrm{Ni}$ solid solution, $\mathrm{Al}_{2} \mathrm{O}_{3}, \mathrm{Ni}_{3} \mathrm{Al}$ and $\mathrm{NiAl}$.

With the increase of atomization pressure, the Ni$\mathrm{Al}$ particle size reduces, thus the porosity of the coating becomes smaller and the bonding strength between coating and substrate increases. On the contrary, with the decrease of atomization pressure, the $\mathrm{Ni}-\mathrm{Al}$ particle size becomes larger, correspondingly the surface roughness becomes larger, and the anti-slip performance and the wear resistance of the coating are therefore improved. By analyzing the morphology of particles in the atomization process, it will play a positive role in guiding the design of spraying processes.

The spraying system used in this experiment is a Praxair/ TAFA controller and model 9935 twin-wire arc spraying gun which is clamped by the manipulator to be sprayed. Before spraying, the surface of specimens should be removed the rust and oil, and roughened treatment. The specimens are cleaned by alcohol or acetone after sand blasting and blown dry by compressed air. The specimens of sand blasting should not be placed more than $4 \mathrm{~h}$ before spraying. Related sandblast parameters before arc spraying are listed in Table $4^{19,20}$. Processing parameters of twin-wire arc spraying are listed in Table $5^{19,20}$. Process of twin-wire arc sprayed Ni-Al coating is shown in Fig. 14a, and a sprayed specimen is shown in Fig. 14b. The thickness of the coating is controlled by the gun speed. The overlap between the coating and the coating should be appropriate. The temperature of the substrate should not exceed $473 \mathrm{~K}$ during the spraying process. The $\mathrm{Ni}-\mathrm{Al}$ coating was successfully prepared by twin-wire arc spraying with the Ni-5wt.\%Al alloy as the bonding layer and $\mathrm{Ni}-20 \mathrm{wt} . \% \mathrm{Al}$ as the surface layer.

Microstructure and surface morphology of the coating were observed by SEM, as shown in Fig. 15a and Fig. 16a. The coating surface shows relatively homogeneous morphology.

Table 3. Processing parameters of obtaining Ni-Al powder.

\begin{tabular}{lcccccc}
\hline $\begin{array}{l}\text { Spraying } \\
\text { materials }\end{array}$ & $\begin{array}{c}\text { Spraying } \\
\text { voltage }(\mathrm{V})\end{array}$ & $\begin{array}{c}\text { Spraying current } \\
(\mathrm{A})\end{array}$ & $\begin{array}{c}\text { Wire diameter } \\
(\mathrm{mm})\end{array}$ & $\begin{array}{c}\text { Spraying } \\
\text { distance }(\mathrm{mm})\end{array}$ & $\begin{array}{c}\text { Spraying time } \\
(\mathrm{s})\end{array}$ & $\begin{array}{c}\text { Air pressure } \\
(\mathrm{MPa})\end{array}$ \\
\hline Ni-5wt.\%Al & 38 & 260 & $\varnothing 1.6$ & 150 & 30 & $0.2 / 0.3 / 0.4$ \\
Ni-20wt.\%Al & 36 & 240 & $\varnothing 1.6$ & 150 & 30 & $0.2 / 0.3 / 0.4$ \\
\hline
\end{tabular}

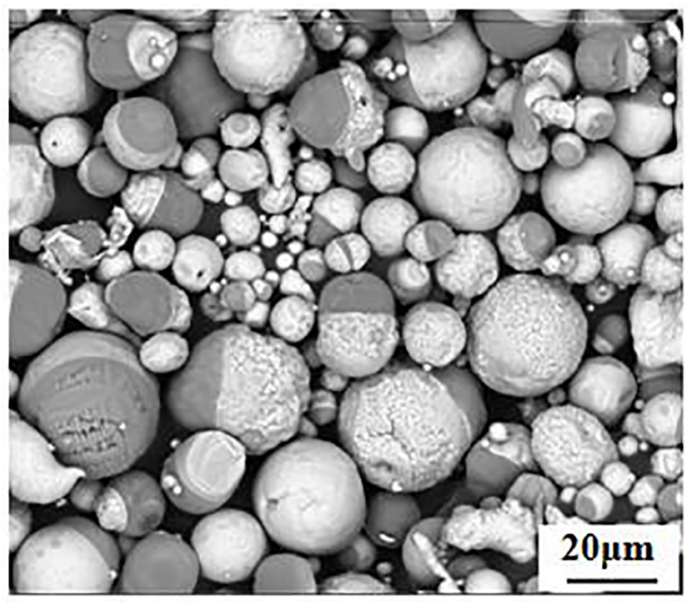

(a) Surface morphology

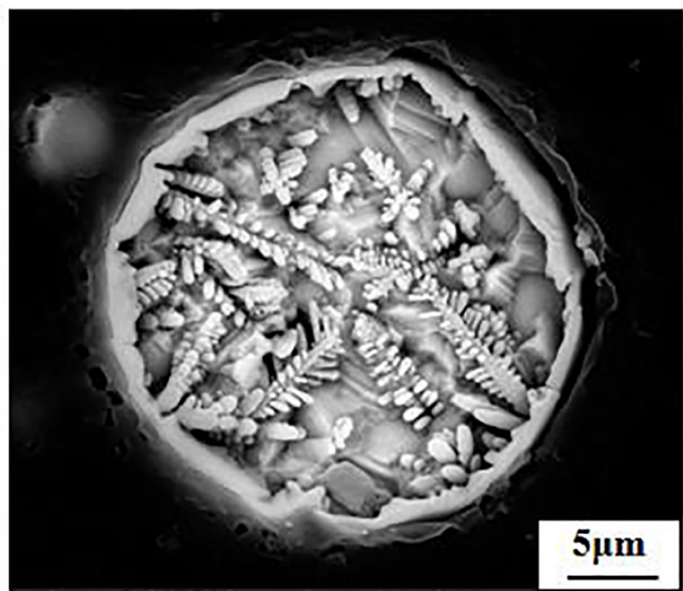

(b) Cross-section morphology

Figure 13. SEM morphology of Ni-Al powder for surface morphology (a) and inner cross-section morphology (b) 
Table 4. Related sand blast parameters before arc spraying process.

\begin{tabular}{cccccccc}
\hline Substrate & Carrier gas & $\begin{array}{c}\text { Sandblast } \\
\text { material }\end{array}$ & $\begin{array}{c}\text { Sand size } \\
(\mathrm{mm})\end{array}$ & $\begin{array}{c}\text { Carrier } \\
\text { pressure } \\
(\mathrm{MPa})\end{array}$ & $\begin{array}{c}\text { Sandblast } \\
\text { distance }(\mathrm{mm})\end{array}$ & $\begin{array}{c}\text { Sandblast } \\
\text { angle }\left({ }^{\circ}\right)\end{array}$ & $\begin{array}{c}\text { Sandblast } \\
\text { time }(\mathrm{s})\end{array}$ \\
\hline $6061-\mathrm{T} 6$ & Air & $\mathrm{Al}_{2} \mathrm{O}_{3}$ & 0.5 & $0.4 \sim 0.6$ & $30 \sim 50$ & 90 & 30 \\
\hline
\end{tabular}

Table 5. Processing parameters of twin-wire arc spraying technique.

\begin{tabular}{lccccccc}
\hline $\begin{array}{l}\text { Spraying } \\
\text { materials }\end{array}$ & $\begin{array}{c}\text { Spraying } \\
\text { voltage (V) }\end{array}$ & $\begin{array}{c}\text { Spraying } \\
\text { current (A) }\end{array}$ & $\begin{array}{c}\text { Wire diameter } \\
(\mathrm{mm})\end{array}$ & $\begin{array}{c}\text { Air pressure } \\
(\mathrm{MPa})\end{array}$ & $\begin{array}{c}\text { Spraying } \\
\text { distance }(\mathrm{mm})\end{array}$ & $\begin{array}{c}\text { Gun speed } \\
\left(\mathrm{mm} \cdot \mathrm{s}^{-1}\right)\end{array}$ & $\begin{array}{c}\text { Coating } \\
\text { thickness } \\
(\mathrm{mm})\end{array}$ \\
\hline Ni-5wt.\%Al & 38 & 260 & $\varnothing 1.6$ & 0.4 & 150 & 300 & 0.15 \\
Ni-20wt.\%Al & 36 & 240 & $\varnothing 1.6$ & 0.4 & 50 & 300 & 0.35 \\
\hline
\end{tabular}

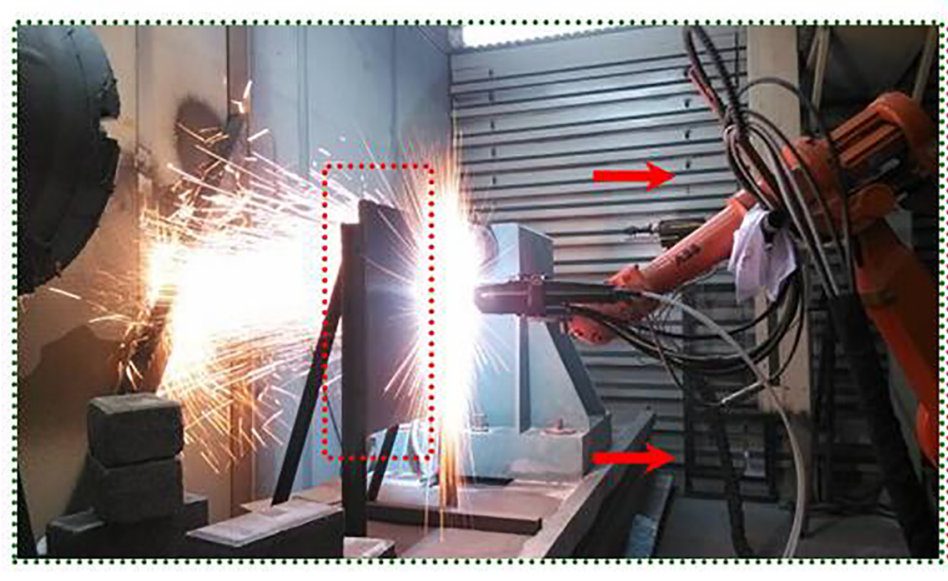

(a) Process of twin-wire arc spraying

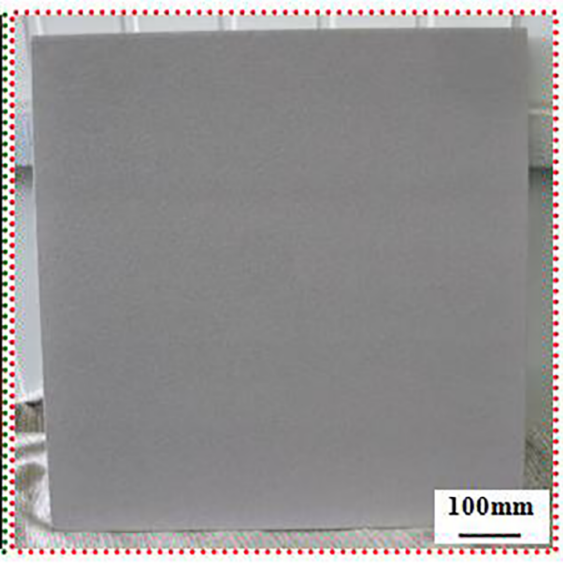

(b) Sprayed specimen

Figure 14. Process of twin-wire arc sprayed $\mathrm{Ni}-\mathrm{Al}$ coating (a) and a sprayed specimen (b)

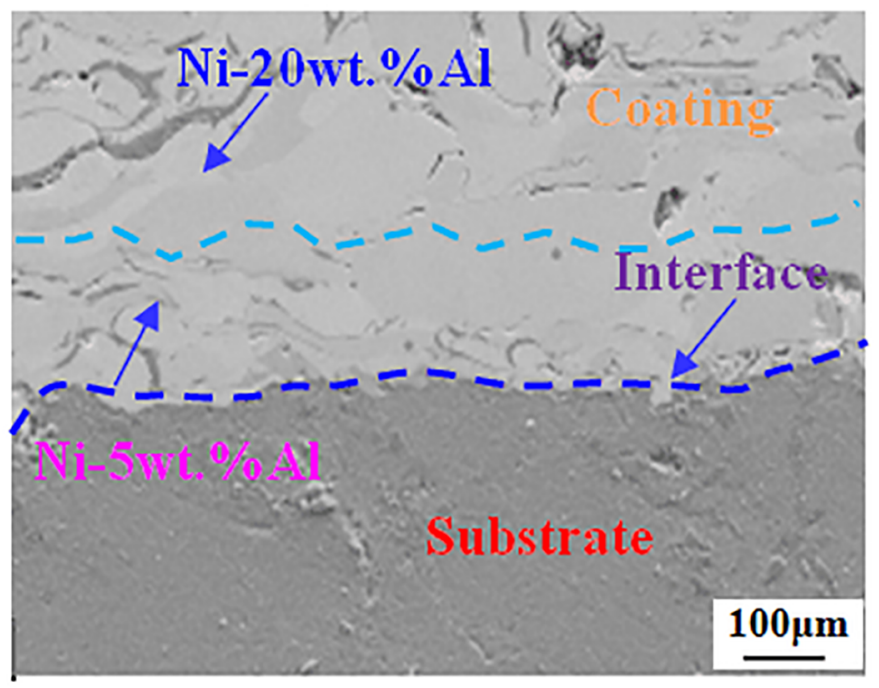

(a) Cross-section morphology
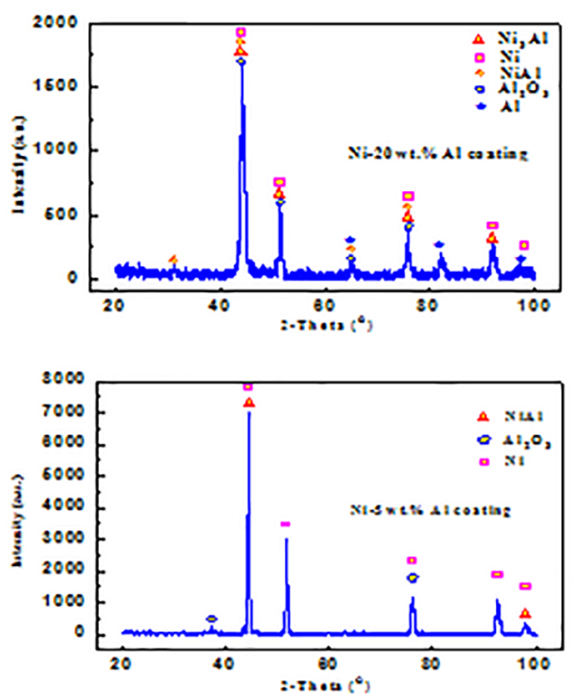

(b) XRD patterns

Figure 15. Cross-section morphology (a) and XRD patterns of Ni-20wt.\%Al and Ni-5wt.\%Al coatings (b) 

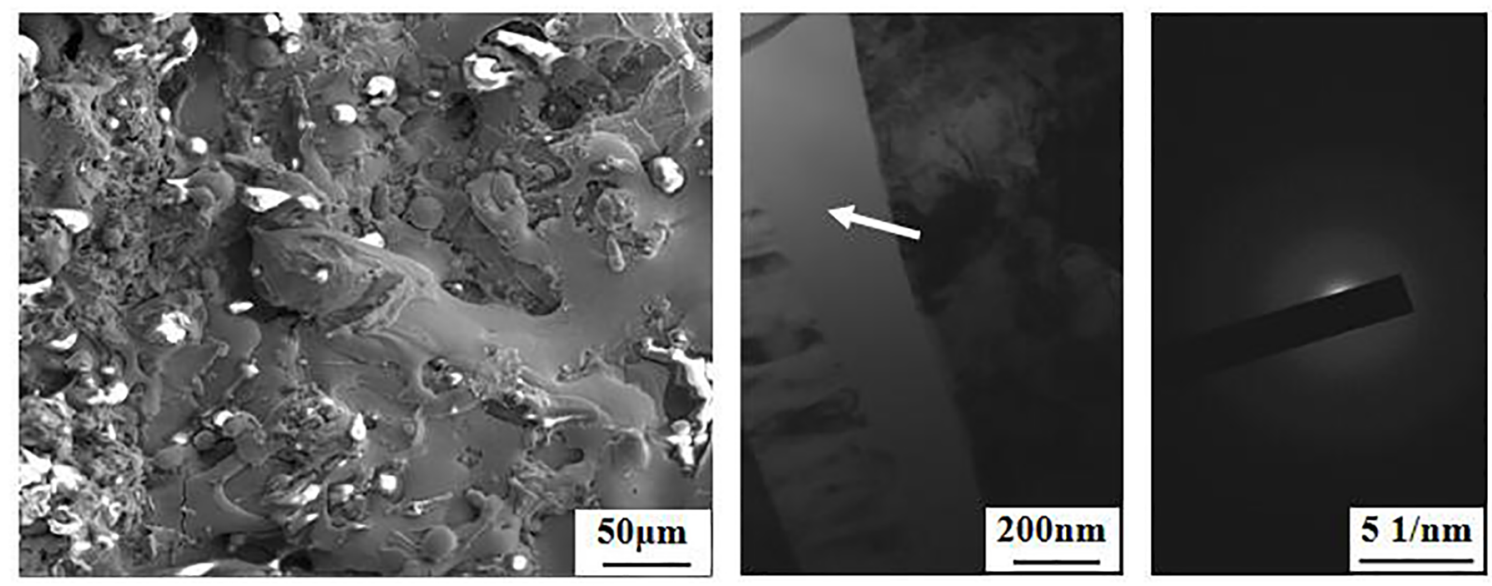

(a) SEM surface morphology (b) TEM morphology

Figure 16. SEM surface morphology of the Ni-Al coatings (a) and TEM morphology(b) and selected-area electron diffraction (c)

XRD patterns of Ni-5wt.\%Al coating and Ni-20wt.\%Al coating are shown in Fig. 15b. It can be seen that the main phase of the Ni-5wt.\%Al coating is Ni solid solution, NiAl and $\mathrm{Al}_{2} \mathrm{O}_{3}$ from the diffraction patterns. The main components of $\mathrm{Ni}-20 \mathrm{wt} . \% \mathrm{Al}$ coating are $\mathrm{Ni}$ solid solution, $\mathrm{NiAl}, \mathrm{Ni}_{3} \mathrm{Al}$, $\mathrm{Al}$ and $\mathrm{Al}_{2} \mathrm{O}_{3}$. Fig. 16b shows the TEM morphology of the original state of $\mathrm{Ni}-\mathrm{Al}$ coating. The selected area electron diffraction in the original coating surface area $(\mathrm{Ni}-20 \mathrm{wt} . \% \mathrm{Al})$ indicates there exists a typically amorphous phase in Fig. 16c. The existence of amorphous is accordingly formed under the more rapid cooling conditions ${ }^{21,22}$.

\section{Conclusions}

The droplet of twin-wire arc spraying is accelerated at the initial stage, then tends to be stable during the gas flow. The temperature of droplet reaches the highest firstly and then decreases rapidly under the air flow actions.

The theoretical model of metal droplets is established based on VOF dual-phase flow model. The droplet shows a breakup model possessing both two stages breakup in the lower velocity and explosive breakup at high velocity.

The main phase of Ni-5wt.\%Al coating obtains $\mathrm{Ni}$ solid solution, $\mathrm{NiAl}$ and $\mathrm{Al}_{2} \mathrm{O}_{3}$. The main composition of $\mathrm{Ni}-20 \mathrm{wt} . \% \mathrm{Al}$ coating is $\mathrm{Ni}$ solid solution, $\mathrm{NiAl}, \mathrm{Ni}_{3} \mathrm{Al}, \mathrm{Al}$ and $\mathrm{Al}_{2} \mathrm{O}_{3}$. Notably, there also exists an amorphous phase in the original coatings.

\section{Acknowledgements}

This research work is financially supported by the Natural Science Foundation of Heilongjiang Province of China (Grant No. JJ2018ZR0314 and QC2015011). Jixiao Wang would like to thank Dr. Vladymyr and Mr. Nikolay, Senior Engineer at Ukraine E.O. Paton Electric Welding Institute for extending their support, and also thank Dr. Yongxiong Chen, at State Key Laboratory for Remanufacturing, the Academy of Armored Forces Engineering, and Dr. Zhiping Wang, Senior Engineer at the College of Science, Civil Aviation University of China, for their useful suggestions and discussions.

\section{References}

1. Gonzalez-Juez ED, Kerstein AR, Ranjan R, Menon S. Advances and challenges in modeling high-speed turbulent combustion in propulsion systems. Progress in Energy and Combustion Science. 2017;60:26-67. DOI: 10.1016/j.pecs.2016.12.003

2. Gañán-Calvo AM, Ferrera C, Montanero JM. Universal size and shape of viscous capillary jets: application to gas-focused micro jets. Journal of Fluid Mechanics. 2011;670:427-438. DOI: $10.1017 /$ S0022112010006476

3. Reinecke WG, Waldman GD. Particle trajectories, heating, and breakup in hypersonic shock layers. AIAA Journal. 2015;9(6):1040-1048. DOI: $10.2514 / 3.6328$

4. Nagy J, Horvath A, Jordan C, Harasek M. Turbulent phenomena in the aero breakup of liquid droplets. CFD Letters. 2012;4(3):112126.

5. Tillmann W, Abdulgader M. Particle size distribution of the filling powder in cored wires: Its effect on arc behavior, In-flight particle behavior, and splat formation. Journal of Thermal Spray Technology. 2012;21(3-4):706-718. DOI: 10.1007/s11666-0129769-7

6. Hu J, Bodard N, Sari O, Riffat S. CFD simulation and validation of self-cleaning on solar panel surfaces with superhydrophilic coating. Future Cities and Environment. 2015;1:8. DOI: 10.1186/ s40984-015-0006-7

7. Blackwell BC, Deetjen ME, Gaudio JE, Ewoldt RH. Sticking and splashing in yield-stress fluid drop impacts on coated surfaces. Physics of Fluids. 2015;27(4):043101. DOI: 10.1063/1.4916620 
8. Kelkar M, Heberlein J. Wire-arc spray modeling. Plasma Chemistry and Plasma Processing. 2002;22(1):1-25. DOI: 10.1023/A:1012924714157

9. Liu J, Xu X. Direct numerical simulation of secondary breakup of liquid drops. Chinese Journal of Aeronautics. 2010;23:153161. DOI: 10.1016/S1000-9361(09)60199-0

10. Lam SP, Abas AW, Ariffin S, Lee WK. Numerical analysis of single phase flow pressure drop in a horizontal rifled tube. Applied Mechanics and Materials. 12;110-116:4398-4405. DOI: 10.4028/www.scientific.net/AMM.110-116.4398

11. Lou JF, Hong T, Zhu JS. Numerical simulation of the drop of the liquid drop in the gas medium. Chinese Journal of Computational Mechanics. 2011;28(2):210-213. DOI: 10.7511/ jslx201102010

12. Wei MR, Wang Y, Liu YC, Wen H, Zhang YS. One-dimension model of droplet evaporation and its application in dimethyl ether spray. Ranshao Kexue Yu Jishu/Journal of Combustion Science and Technology. 2005;11(1):14-18.

13. Liang Y, Sheng YS. Investigation of breakup of liquid droplet in gas medium using LES/VOF method. Aeronautical Computing Technique. 2012;42(6):58-61. DOI: 10.3969/j.issn.1671654X.2012.06.015

14. Onuaguluchi O, Eren Ö. Cement mixtures containing copper tailings as an additive: durability properties. Materials Research. 2012;15(6):1029-1036. DOI: 10.1590/S1516-14392012005000129

15. Skordaris G, Bouzakis KD, Charalampous P. A dynamic FEM simulation of the nano-impact test on mono-or multi-layered PVD coatings considering their graded strength properties determined by experimental-analytical procedures. Surface and Coatings Technology. 2015;265:53-61. DOI: 10.1016/j. surfcoat.2015.01.063
16. Mahfouz RM, Al-Ahmari S, Al-Fawaz A, Al-Othman Z, Warad IK, Siddiqui MRH. Kinetic analysis for non-isothermal decomposition of unirradiated and $\gamma$-irradiated indium acetyl acetonate. Materials Research. 2011;14(1):7-10. DOI: 10.1590/ S1516-14392011005000009

17. Ferreira AF, Tomaskewski IMS, Paradela KG, Silva DMD, Sales RC. Numerical simulation of microstructural evolution via phase-field model coupled to the solutal interaction mechanism. Materials Sciences and Applications. 2015;6:907-923. DOI: 10.4236/msa.2015.610092

18. Peery KM, Forester CK. Numerical simulation of multi stream nozzle flows. AIAA Journal. 1980;18(9):1088-1093. DOI: $10.2514 / 3.50858$

19. Wang JX, Liu JS, Zhang LY, Sun JF, Wang ZP. Microstructure and mechanical properties of twin-wire arc sprayed $\mathrm{Ni}$-Al composite coatings on 6061-T6 aluminum sheet. International Journal of Minerals, Metallurgy and Materials. 2014;21(5):469-478. DOI: $10.1007 / \mathrm{s} 12613-014-0931-8$

20. Wang JX, Wang GX, Liu JS, Zhang LY, Wang W, Li Z, et al. Microstructure of Ni-Al powders and $\mathrm{Ni}-\mathrm{Al}$ composite coatings prepared by twin-wire arc spraying. International Journal of Minerals, Metallurgy and Materials. 2016;23(7):810-818. DOI: 10.1007/s12613-016-1295-z

21. Bostani B, Arghavanian R, Parvini-Ahmadi N. Study on particle distribution, microstructure and corrosion behavior of $\mathrm{Ni}-\mathrm{Al}$ composite coatings. Materials and Corrosion. 2015;63(4):323327. DOI: $10.1002 /$ maco. 201005912

22. Liu K, Li Y, Wang J. In-situ reactive fabrication and effect of phosphorus on microstructure evolution of $\mathrm{Ni} / \mathrm{Ni}-\mathrm{Al}$ intermetallic composite coating by laser cladding. Materials \& Design . 2016;105:171-178. DOI: 10.1016/j.matdes.2016.05.074 